\title{
Aquatic versus Land-Based Exercise in Treatment of Chronic Mechanical Low Back Pain
}

\author{
HEND M.T. NASAR, M.Sc.*; RAGIA M. KAMEL, Ph.D.** and NABIL M. ABEDL-AAL, Ph.D.** \\ The Department of Physical Therapy, National Institute for Neuromotor System (Embaba) * and \\ The Department of Basic Sciences, Faculty of Physical Therapy, Cairo University**, Egypt
}

\begin{abstract}
Background: Mechanical Low Back Pain (MLBP) is a major cause of illness and disability, especially in people of working age.

Aim of Study: The study was conducted to compare between the effect of aquatic exercise and land-based exercises on pain level, functional disability and lumbar Range of Motion (ROM) in subjects with Chronic Mechanical Low Back Pain (CMLBP).
\end{abstract}

Material and Methods: Sixty patients with chronic mechanical low back pain of both gender participated in the study: 17 male and 43 female between 25 and 40 years old. They were divided randomly and equally into two groups: A study group (A), in which patients received land based exercise program; and study group (B), in which patients received aquatic exercise program. Both groups received the treatment program for 50min, three times per week, for one month assessment of patients in each group for pain level, functional disability and lumbar range of motion before and after treatment.

Results: There were statistically significant differences in all outcome measures in favor of the water exercises group $(p<0.001)$. In land exercise group, there were statistically significant differences regarding pain intensity, oswestry disability index, and lumbar flexion $(p<0.0001)$, except for extension, right and left side bending range of motion outcomes $(p>0.05)$. However, there were statistically significant differences regarding all outcome measure in water exercise group $(p<0.0001)$ when comparing the pre-treatment with posttreatment results.

Conclusion: Aquatic therapy is effective in decreasing pain severity, level of functional disability and improved lumbar range of motion in patient with chronic mechanical low back pain than land-based exercise.

Key Words: Low back pain - Range of motion - Disability Hydrotherapy - Exercise.

\section{Introduction}

MECHANICAL Low Back Pain (MLBP) is a major cause of illness and disability, especially in

Correspondence to: Dr. Hend M.T. Nasar,

E-Mail: Dr.didibdr@gmail.com people of working age. By definition, it excludes pain resulting from neoplasia, fracture or inflammatory arthropathy, or that is referred from anatomical sites outside the spine and in most cases there is no clearly demonstrable underlying pathology [1]. Mechanical low back pain that lasts at least one day and limits activity is a very common and widespread complaint. It affects men and women equally. Over a lifetime, $80 \%$ of people have lower back pain, with the difficulty most often beginning between 30 and 40 years old [2] Living sedentary life and lack of physical fitness makes human liable to back pain. The cause of lower spine being so commonly affected could be due to inherent skeletal abnormalities, poor posture, inability of lumbar spine musculature to control movements and protect against injury [3] .

Aquatic therapy is an intervention technique that involves utilizing activities to promote physical and cognitive rehabilitation. Aquatic intervention typically takes place in pools of various sizes where participants have enough room to stand and perform exercises [4]. Warm water may enhance blood flow, which is thought to help in dissipating allogeneic chemicals, and facilitate muscle relaxation. In addition, the hydrostatic effect may relieve pain by reducing peripheral edema and by dampening sympathetic nervous system activity [5]

Aquatic therapy has been used for many years in the management of musculoskeletal problems including low back pain. Water immersion decreases axial loading of the spine and, through the effects of buoyancy, allows the performance of movements that are normally difficult or impossible on land [6]. Exercise therapy on land targeting spinal and trunk musculature commonly Forms the foundation of clinical programs for people with Chronic LBP (CLBP) and has been shown to reduce pain and 
disability and improve muscle function and strength [7]. Exercise is believed to be an important component of CLBP management as deconditioning and muscle weakness as well as atrophy due to disuse may contribute to the associated disability.

Previous literatures stated that engaging in general group exercises such as strengthening and aerobic conditioning as well as individually supervised specific spinal stabilization exercises have been reported to decrease the intensity of LBP and protect against recurrence [8]. Other literature stated that aquatic exercise could be considered another effective therapeutic instrument in preventing and treating LBP as in water it is possible to perform actions and movements which cannot be performed in an environment which is governed by the law of physics, reducing muscle tension and the weight of the individual [9].

Aim of study:

To compare between the effect of aquatic and land-based exercises on pain level, functional ability and lumbar range of motion in patients with chronic mechanical low back pain.

\section{Material and Methods}

Design of the study:

The study was a pretest-posttest research design.

\section{Participant:}

Participants were recruited from outpatient clinic of the National Institute for Neuromotor System (Embaba), Egypt. The clinical application of both aquatic and land-based exercise group were conducted in in the Specialized Center for Rehabilitation, Physical Therapy and Hydrotherapy (ElMohandsen), Cairo, Egypt. In the period between October 2019 to March 2020. The study was approved by the Ethical Committee for Human Research at Faculty of Physical Therapy, Cairo University, Egypt. (Reference number P.T. REC/012/ 002835). Participants were invited to join the study and signed the written consent form prior to participation.

Sixty patients diagnosed with mechanical low back pain for more than three months, were enrolled to the study if they met the inclusion criteria of being between the age of 25 to 40 years, their BMI $<30 \mathrm{Kg} / \mathrm{m}^{2}$ [10], pain localized to the lumbosacral region without radicular pain, medically stable (vital signs are stable within normal limits: Blood pressure, pulse, temperature, and respiration) and not be treated with analgesics or any medication which may cause misleading results. Patients were excluded if they had structural discrepancy as leg length discrepancy, previous back surgery, spinal infection, neurologic deficit, pregnancy, spondylolisthesis, hip orthosis, ankylosing spondylitis or rheumatoid arthritis, infective or inflammatory disease, abnormal blood pressure, open wounds, urinary, sever cardiac disease, current or recurrent radiation treatment, sever osteoporosis.

\section{Sample size and randomization:}

A priori sample size has been calculated by G*Power (Dusseldorf, Germany) to find out a difference of $20 \%$ of pain intensity $(20 \mathrm{~mm})$ between the study groups using the Visual Analogue Scale (VAS), with the calculated power analysis of $80 \%$ and a two-sided 5\% significance level. Therefore, the sample size was calculated to be 26 patients for each group and the number was increased by $15 \%$ to be 30 to consider the drop out from the time of randomization to the end of the treatment protocol. Sixty patients were randomly assigned to receive a land-based exercise program (Group $\mathrm{A}=30$ ) or aquatic exercise program (Group $\mathrm{B}=30$ ) using a computer generated random blocks and concealed allocation was done by the use of sealed opaque envelopes. A randomization generated by an author not involved in data collection.

\section{Instrumentation:}

\section{A- For evaluation:}

- Visual analogue scale to assess pain.

- Oswestry Disability Index (ODI) to evaluate functional disabilities.

- Modified-Modified Schober Test (MMST) to evaluate lumbar flexion and extension range of motion.

- Finger-to-floor technique to evaluates lateral spinal flexion of motion.

\section{$B$ - For treatment:}

Study group (A): Land-based exercise group:

The patient performing the exercises using the floor of the gymnasium of the out-patient unit.

\section{Study group (B): Aquatic exercise therapy:}

- Aquatic therapy program was carried out in an indoor pool sized $270 \times 350 \mathrm{~cm}$, with $130 \mathrm{~cm}$ water depth (Hydrotherapy Department of The Specialized Center for Rehabilitation, Physiotherapy and Hydrotherapy).

- Swimming pool thermometer to adjust water temperature to be around $32^{\circ} \mathrm{C}-34^{\circ} \mathrm{C}$.

- Noodles, kick board and sand bags devices were used for upper-body and lower-body exercises. 


\section{Procedure:}

Each patient was interviewed and the goal of the study was explained, the patient that agreed to participate in the study was asked to fill a consent form. Detailed history was taken from each patient. Pain intensity, lumbar range of motion and functional disability were assessed for each patient before and at the end of treatment sessions.

\section{A- Evaluation procedures:}

- Evaluate pain intensity using the VAS which is consisted of a horizontal line $100 \mathrm{~mm}$ in length, with the end points No pain and Worst possible pain placed at each end of the line. Respondents were asked to make a mark on the line that indicated their usual pain [11]. VAS is a valid and reliable tool to measure pain intensity [12]

- Evaluate functional disabilities using Oswestry Disability Index (ODI) as it is represented by 10 domains of activities in daily life (pain intensity, personal care, lifting, walking, sitting, standing, sleeping, sex life, social life and travelling). Each domain or item consists of 6 statements (score, 0-5) and is scored by the patient in reference to his/her current functional status. Each question is rated on a scale $0-5,0$ being no disability and 5 representing the greatest amount of disability [13]. ODI version 2.0 proved to be reliable and valid. As it is easy for the patient to administer and to score both in clinical work and research [14].

- Measure flexion and extension of lumbar spine using the Modified-Modified Schober Test (MMST) the starting position of measurement was standing with hips and knees in neutral position and the distance between feet should be equal to the shoulder's width. The tape was aligned from baseline landmark (at the middle of spine in line between both sides of PSIS) to $15 \mathrm{~cm}$ above the baseline landmark. The subjects moved both hands down as far as possible while keeping knees extended. The investigator recorded the difference of distance between the superior and the baseline landmarks by subtracting from $15 \mathrm{~cm}$ while the subject fully flexed or extended [15] Modified Modified Schober Test is reliable, valid and convenient for both therapist and patient as it does not need any fixation and landmarks are easy to palpate [16].

- Measure lateral spinal flexion of motion using finger-to-floor technique. As subjects stood on the floor with arms in the neutral position, heels together, knees and back straight. Subjects bent toward the right with elbow and fingers straight and attached hand on their lateral side of leg. The distance between the tip of third finger and the floor was measured [17]. The high levels of intrarater reliability and concurrent validity, demonstrate the FFD to be reproducible and a valid measure of lateral flexion range of motion [18].

\section{B- Treatment procedure:}

According to the program of Bello et al., 2010 [19] and Sawant and Shinde 2019 [20] . A specific exercise was prescribed for each group with approach of warming-up, main exercise and cooling down phase.

Study group $(A)$ : This group received Land based exercise which was performed in three phases, namely: Warming up phase, main exercise phase and cool down phase. (1) Warming-up: Comprised of 3 min walking in the gym forward, backward and sideways. (2) Main exercise phase: Comprised of stretching exercises for lower back in the form of single knee to chest and double knee to chest exercise, hamstring stretch and lateral rotator of trunk. Spinal stabilization exercises to strengthen both multifidus and transversus abdominus from supine Pelvic bridging, from quadruped position Alternate arm and leg raise, from Prone straight leg raise, back extension, arm raise, alternate arm and leg raise. Abdominal curl ups from supine. (3) Cooling down: Comprised of 3 min walking in the gym forward, backward and sideways.

Study group $(B)$ : This group received aquatic exercise which was performed in three phases, namely: Warming up phase, main exercise phase and cool down phase. (1) Warming-up: Comprised of $2 \mathrm{~min}$ of pool walking forward, backward and sideways. (2) Main exercise-phase: Comprised of stretching exercise for lower back in the form of single knee to chest, stretching for lateral rotator of trunk, hamstring, gastrocnemius, hip adductors and superman stretch. Strengthening exercise for the abdomen, lower back, glutei, lateral rotator of trunk, lower limb and upper limb, knee in the form of squatting, lunges forward and sideway, toe raising, one leg balance kickboard oblique, hip flexion, abduction and extension, bicycle kicks, noodle bicycle kick, knee curls, kickboard push shoulder flexion, extension, abduction and adduction, shoulder horizontal abduction and adduction, pool noodle knee extensions. (3) Cooling down: Comprised of $2 \mathrm{~min}$ of pool walking forward, backward and sideways.

\section{Statistical analysis:}

The measured variables were statistically analyzed and compared using SPSS for windows 
version 25 (SPSS, Inc., Chicago, IL) with Alpha level set at 0.05 . Data were screened for normality assumption, homogeneity of variance, and presence of extreme scores. Shapiro-Wilks test for normality showed that the measured variables were normally distributed $(p>0.5)$. Data are expressed as mean and standard deviation for are outcomes except for gender (counts). Two-way mixed design MANOVA were used to compare among the groups on the combined effect of all outcomes. When MANOVA is statistically significant, follow-up with univariate ANOVAs for every outcome with Bonferroni correction to protect against type I error.

\section{Results}

The results showed no statistically significant differences between groups regarding visual analogue scale (pain intensity), oswestry disability index, and lumbar flexion, extension, right and left side bending range of motion outcome measures $(p>0.05)$.

Repeated measures multivariate analysis was conducted to assess the difference between participants in the land exercises group and participants in the water exercises group in the amount of change in their scores on the outcome measures. Statistically significant multivariate effects were found for the main effects of groups, Wilk's $\mathrm{A}=$ $0.41, \mathrm{~F}(6,53)=12.62, p<0.001, \eta^{2}=0.59$, for time, Wilk's $A=0.03, \mathrm{~F}(6,53)=322.4, p<0.001, \eta^{2}=0.97$, as well as for the interaction between groups and time, Wilk's $\mathrm{A}=0.13, \mathrm{~F}(6,53)=59.5, p<0.001, \eta^{2}=$ 0.87 .
Follow-up univariate ANOVAs reveal that significant change for $\mathrm{VAS}_{2}$ outcome variable, $\mathrm{F}(1$, $58)=1476.32, p<0.001, \eta=0.96$, for ODI outcome variable, $\mathrm{F}(1,58)=450.51, p<0.001, \eta^{2}=0.89$ and for flexion outcome variable, $\mathrm{F}(1,58)=392.77$, $p<0.001, \eta^{2}=0.87$, for extension, $\mathrm{F}(1,58)=68.66$, $p<0.001, \eta=0.54$, right lateral flexion outcome variable, $F(1,58)=20.59, p<0.001, \eta^{2}=0.26$, for left lateral flexion outcome variable, $\mathrm{F}(1,58)=$ 28.43, $p<0.001, \eta^{2}=0.33$. This interaction effect indicates that the difference between the land exercises and water exercises groups on the linear combination of the outcome measures is different at pretest than posttest. Examination of the means suggests that this is because groups do not differ on either dependent variable at the time of the pretest, but they do differ at the time of the posttest.

\section{Between-group comparison:}

There was no significant difference between the land exercises and water exercises groups in all outcomes before treatment $(p>0.05)$. After 4 weeks of intervention, there were statistically significant differences in all outcome measures in favor of the water exercises group $(p<0.001)$. Negative mean difference scores $(95 \% \mathrm{CI})$ on flexion and extension measures are indicative of improvement, whereas positive change scores $(95 \%$ CI) on VAS, ODI, right and left lateral flexion outcome measures indicate improvement. The water exercises group showed superiority to the land exercises group after four weeks of intervention for all outcome measures $(p<0.001)$ as shown in (Tables 1,2).

Table (1): Baseline clinical characteristics of subjects $(\mathrm{N}=60)^{*}$.

\begin{tabular}{|c|c|c|c|c|c|c|}
\hline Characteristics & $\begin{array}{l}\text { Land Ex's Group } \\
\qquad(\mathrm{n}=30)\end{array}$ & \multicolumn{2}{|c|}{$\begin{array}{l}\text { Water Ex's Group } \\
\qquad(\mathrm{n}=30)\end{array}$} & MD & $95 \% \mathrm{CI}$ & $\begin{array}{c}p- \\
\text { value }\end{array}$ \\
\hline VAS (mm) & $65.9 \pm 5.49$ & \multicolumn{2}{|c|}{$67.97 \pm 8.97$} & -2.07 & $(-5.91,1.78)$ & 0.29 \\
\hline ODI & $34.33 \pm 4.77$ & \multicolumn{2}{|c|}{$35.57 \pm 9.99$} & -1.23 & $(-5.28,2.81)$ & 0.54 \\
\hline Flex $(\mathrm{cm})$ & $4.24 \pm 1.46$ & \multicolumn{2}{|c|}{$4.9 \pm 1.33$} & -0.66 & $(-1.38,0.07)$ & 0.07 \\
\hline Ext. (cm) & $2.5 \pm 0.94$ & \multicolumn{2}{|c|}{$2.6 \pm 0.82$} & -0.1 & $(-0.56,0.36)$ & 0.66 \\
\hline RLF (cm) & $46.55 \pm 3.4$ & \multicolumn{2}{|c|}{$48.13 \pm 4.14$} & -1.58 & $(-3.54,0.38)$ & 0.11 \\
\hline $\operatorname{LLF}(\mathrm{cm})$ & $49.2 \pm 3.5$ & \multicolumn{2}{|c|}{$49.0 \pm 3.98$} & -0.2 & $(-1.74,2.14)$ & 0.84 \\
\hline \multicolumn{2}{|c|}{ VAS : Visual Analogue Scale. } & RLF & : Right L & ral Flexi & & \\
\hline \multicolumn{2}{|c|}{ ODI : Oswestry Disability Index. } & MD & Mean D & erence. & & \\
\hline \multicolumn{2}{|c|}{ Flex : Flexion. } & Ex's & : Exercis & & & \\
\hline \multicolumn{2}{|c|}{ Ext : Extension. } & $\mathrm{CI}$ & : Confid & e Interva & & \\
\hline \multicolumn{2}{|c|}{ LLF : Left Lateral Flexion. } & $p$-val & : Probab & y value. & & \\
\hline
\end{tabular}


Table (2): Clinical characteristics of subjects in both groups after 4 weeks $(\mathrm{N}=60)^{*}$.

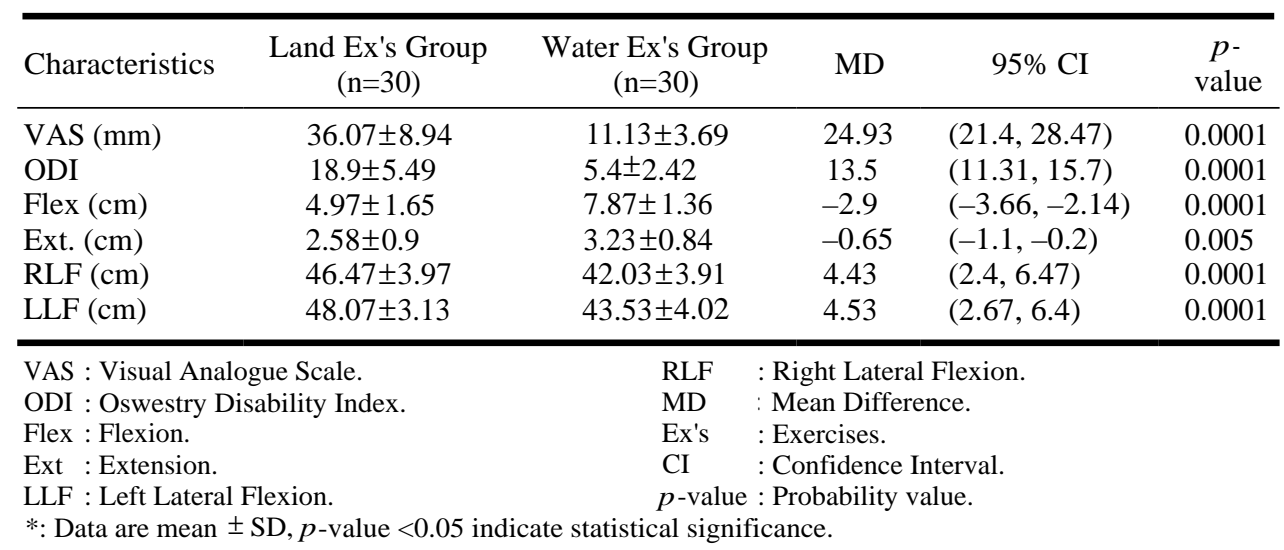

\section{Within-group comparison:}

In land exercise group, there were statistically significant differences regarding visual analogue scale (pain intensity), oswestry disability index, and lumbar flexion $(p<0.0001)$, but no statistically significant differences regarding extension, right and left side bending range of motion outcomes $(p>0.05)$ when comparing the pre-treatment with post-treatment results. However, there were statistically significant differences regarding visual analogue scale (pain intensity), oswestry disability index, and lumbar flexion, extension, right and left side bending range of motion outcome measures in water exercise group $(p<0.0001)$ when comparing the pre-treatment with post-treatment results as shown in (Table 3 ).

Table (3): Within group changes at pre, after 4 weeks of intervention.

\begin{tabular}{|c|c|c|c|c|}
\hline \multirow{2}{*}{ Outcomes } & \multicolumn{2}{|c|}{$\begin{array}{l}\text { Land Ex's Group }(n=30) \\
\text { Change from baseline to } 4 \text { weeks }\end{array}$} & \multicolumn{2}{|c|}{$\begin{array}{l}\text { Water Ex's Group }(n=30) \\
\text { Change from baseline to } 4 \text { weeks }\end{array}$} \\
\hline & $\mathrm{MD}(95 \% \mathrm{CI})$ & $p$-value & MD $(95 \% \mathrm{CI})$ & $p$-value \\
\hline VAS (mm) & $-29.83(-33.03,-26.64)$ & $<0.0001$ & $-56.8(-60.03,-53.64)$ & $<0.0001$ \\
\hline ODI & $-15.4(-18.47,-12.39)$ & $<0.0001$ & $-30.2(-33.21,-27.13)$ & $<0.0001$ \\
\hline Flex $(\mathrm{cm})$ & $0.72(0.46,0.99)$ & $<0.0001$ & $2.97(2.70,3.23)$ & $<0.0001$ \\
\hline Ext. (cm) & $0.08(-0.04,0.21)$ & 0.18 & $0.63(0.51,0.76)$ & $<0.0001$ \\
\hline $\operatorname{RLF}(\mathrm{cm})$ & $-0.08(-2.01,1.85)$ & 0.93 & $-6.1(-8.03,-4.17)$ & $<0.0001$ \\
\hline LLF (cm) & $-1.13(-2.89,0.62)$ & 0.2 & $-5.47(-7.22,-3.72)$ & $<0.0001$ \\
\hline \multicolumn{5}{|c|}{ VAS : Visual Analogue Scale. } \\
\hline \multicolumn{5}{|c|}{ ODI : Oswestry Disability Index. } \\
\hline \multicolumn{2}{|c|}{$\begin{array}{l}\text { Flex : Flexion. } \\
\text { Ext }: \text { Extension. }\end{array}$} & Ex's & Exercises. & \\
\hline \multicolumn{2}{|c|}{ Ext : Extension. } & CI & Confidence Interval. & \\
\hline LLF : Left L & 1 Flexion. & $p$-value & Probability value. & \\
\hline
\end{tabular}

\section{Discussion}

Aquatic exercise has become popular for fitness enhancement, general conditioning programs, and rehabilitation for patients with low back pain, those with rheumatic diseases, and the elderly [21]. The aim of the current study was to compare between the effect of aquatic exercise and land-based exercises on pain level, functional disability and lumbar Range of Motion (ROM) in subjects with Chronic Mechanical Low Back Pain (CMLBP).

The main findings of the current study showed that the water exercises group showed superiority to the land exercises group after four weeks of intervention for all outcome measures $(p<0.001)$. In land exercise group showed improvement in pain intensity, oswestry disability index, and lumbar flexion $(p<0.0001)$, with no difference in extension, right and left side bending range of motion outcomes $(p>0.05)$ however there were an improvement in all out come measures in water exercise group when comparing the pre-treatment with posttreatment result after one month of intervention.

The results of the current study revealed significant reduction in pain level in both group with the superiority of aquatic group to land group after one month of intervention. The reduction in aquatic group approved in many studies which concluded 
that warm water can lead to a pain modulation, since pain threshold increases with temperature probably for both sensory overflow and thermo receptor stimulation, which were illustrated in many studies [22-24]. While the reduction in land group approved in many studies which concluded that low abdominal muscular weakness is considered a reason for low back pain; thus, increasing the muscular strength may be an effective in decreasing pain which were illustrated in many studies $[25,26]$

Also, the current study revealed significant improvement in functional disability in both groups with the superiority of aquatic group to land based exercise group. This was approved in many studies which concluded that hydrotherapy provides the optimal environment for patients to exercise aerobically, and at higher intensities than would be possible on land, owing to the reduction of joint loading which were illustrated in many studies [2729]. While the improvement in the land group approved in a study which concluded that exercise produces large reductions in pain and disability [30].

Also, the current study revealed significant improvement in lumbar range of motion in aquatic groups. This may be explained by the effects of aquatic exercise as it cause significantly more flexibility and muscle strength, as the trunk and back muscles being more active during the aquatic exercise to maintain correct body position, resulting in more increasing in range of motion which were illustrated in many studies [31-33].

Furthermore, there were no significant differences in the land group in lumbar extension and lateral side flexion which were in contrast with other study that concluded that land based exercise in the form of hamstring stretches, back stretches, double-knee to chest exercises, and lumbar rotations worked to decrease muscle tightness and subsequently improve range of motion [34]

Also, aquatic therapy decreased the level of back pain, disability and improved lumbar range of motion as the buoyancy of water can eliminate the gravitational forces to counteract body weight, which reduces the amount of joint stress to perform exercises with little effort and less pain sensation. It also can provide the greater range of movement that is required for lifting heaviest body limb or legs during exercise this was in line with other studies $[35,36]$. These findings are in line with previous studies with different water-based exercise intervention program that could recover pain in- tensity and musculoskeletal disability conditions in non-obese population $[37,38]$.

The current study revealed the superioty of aquatic exercise to land based exercise. This was in agreement with previous study which concluded that water based exercises produce better improvement in disability and quality of life of the patients with chronic low back pain than land based exercises [39]

The current study results were in contrast with other study which concluded that aquatic therapy were found to be effective in improving functional status but were not superior to land [40]. And hydrotherapy can reduce pain and improve functional abilities, but no significant improvement was observed in thoracolumbar mobility [41]

Some limitations of this study should be considered. First, the lack of a control group to compare with the 2 exercise treatment groups. Second, further work is recommended to identify the longterm effects of exercising in water versus land. Moreover, the study did not evaluate the quality of life which is one of the most important goals of every therapeutic intervention.

\section{Conclusion:}

Aquatic therapy is effective in decreasing pain severity, level of functional disability and improved lumbar range of motion in patients with chronic mechanical low back pain than land-based exercise.

\section{References}

1- ENDEAN A., PALMER K.T. and COGGON D.: Potential of magnetic resonance imaging findings to refine case definition for mechanical low back pain in epidemiological studies: A systematic review. Spine, 36 (2): 160-9, 2011.

2- CASAZZA B.A.: Diagnosis and treatment of acute low back pain. American Family Physician, 85 (4): 343-50, 2012.

3- SPROUSE R.: Current treatment recommendations for acute and chronic undifferentiated low back pain. Prim. Care: Clinics in office practice, Elsevier, 39 (3): 481-6, 2012.

4- SANDERS M.E., ISLAM M.M., NARUSE A., TAKESHIMA N. and ROGERS M.E.: Aquatic exercise for better living on land: Impact of shallow-water exercise on older Japanese women for performance of Activities of Daily Living (ADL). International Journal of Aquatic Research and Education, 10 (1): 1, 2016.

5- KAMIOKA H., TSUTANI K., OKUIZUMI H., MUTOH Y., OHTA M., HANDA S. and HONDA T.: Effectiveness of aquatic exercise and balneotherapy. A summary of systematic reviews based on randomized controlled trials of water immersion therapies. Journal of Epidemiology, 20 (1): 2-12, 2010. 
6- ZAMENI L. and HAGHIGHI M.: The Effect OF Aquatic Exercise on Pain and Postural Control in Women with low Back Pain. International Journal of Sport Studies, 1 (4): 152-6, 2011.

7- PSYCHARAKIS S.G., COLEMAN S.G., LINTON L., KALIARNTAS K. and VALENTIN S.: Muscle activity during aquatic and land exercises in people with and without low back pain. Physical Therapy, 99 (3): 297 $310,2019$.

8- MAHER and CHRIS G.: Effective physical treatment for chronic low back pain. Orthopedic Clinics, 35 (1): 57 64, 2004.

9- WALLER B., LAMBECK J. and DALY D.: Therapeutic aquatic exercise in the treatment of low back pain: A systematic review. Clin. Rehabil., 23 (1): 3-14, 2009.

10- HOMAYOUNI K., NASERI M., ZARAVAR F., ZARAVAR L. and KARIMIAN H.: Comparison of the effect of aquatic physical therapy and conventional physical therapy in patients with lumbar spinal stenosis (a randomized controlled trial). Journal of Musculoskeletal Research, 18 (01): 1550002, 2015.

11- FERREIRA-VALENTE M.A., PAIS-RIBEIRO J.L. and JENSEN M.P.: Validity of four pain intensity rating scales. Pain®, 152 (10): 2399-404, 2011.

12- KARCIOGLU O., TOPACOGLU H., DIKME O. and DIKME O.: A systematic review of the pain scales in adults: Which to use? The American journal of emergency medicine, 36 (4): 707-14, 2018.

13- SALTYCHEV M., MATTIE R., McCORMICK Z., BÄRLUND E. and LAIMI K.: Psychometric properties of the oswestry disability index. International Journal of Rehabilitation Research, 40 (3): 202-8, 2017.

14- PEKKANEN L., KAUTIAINEN H., YLINEN J., SALO P. and HÄKKINEN A.: Reliability and validity study of the Finnish version 2.0 of the Oswestry Disability Index. Spine, 36 (4): 332-8, 2011.

15- SAKULSRIPRASERT P., VACHALATHITI R., VONGSIRINAVARAT M. and PICHAISAK W.: Responsiveness of pain, active range of motion, and disability in patients with acute nonspecific low back pain. Hong Kong Physiotherapy Journal, 29 (1): 20-4, 2012.

16- SAIDU I.A., MADUAGWU S.M., ABBAS A.D., ADETUNJI O.O. and JAJERE A.M.: Lumbar spinal mobility changes among adults with advancing age. Journal of mid-life health, 2 (2): 65-71, 2011.

17- YOSHIDA A. and LEAMOR K.: The effect of kinesio taping on lower trunk range of motions. Research in sports medicine, 15 (2): 103-12, 2007.

18- HECIMOVICH M.D. and HEBERT J.J.: Reliability and concurrent validity of an alternative method of lateral lumbar range of motion in athletes. South African Journal of Sports Medicine, 28 (1): 23-6, 2016.

19- BELLO A.I., KALU N.H., ADEGOKE B.O. and AGYEPONG-BADU S.: Hydrotherapy versus land-based exercises in the management of chronic low back pain: A comparative study. Journal of musculoskeletal research, 13 (04): 159-65, 2010.

20- SAWANT R.S. and SHINDE S.B.: Effect of hydrotherapy based exercises for chronic nonspecific low back pain. Indian J. Physiother. Occup. Ther., 13 (1): 150-4, 2009.
21- KIM Y.S., PARK J. and SHIMM J.K.: Effects of aquatic backward locomotion exercise and progressive resistance exercise on lumbar extension strength in patients who have undergone lumbar discectomy. Archives of physical medicine and rehabilitation, 91 (2): 208-14, 2010.

22- JANYACHAROEN T., CHAICHANAWONGSA J., NAMSIRI S., THONGDUANG Y., ARAYAWICHANOND P. and KANPITTAYA J.: Effects of aquatic exercise on trunk flexibility, back muscle strength, and pain scale in chronic nonspecific low back pain patients. Chula Med. J. Jul.-Aug., 56 (4): 433-45, 2012.

23- HALL J., GRANT J., BLAKE D., TAYLOR G. and GARBUTT G.: Cardiorespiratory responses to aquatic treadmill walking in patients with rheumatoid arthritis. Physiother. Res. Int., 9 (2): 59-73, 2012.

24- VERSTAPPEN F.T., SANTEN-HOEUFT H.M., BOLWIJN P.H., VAN DER LINDEN S. and KUIPERS H.: Effect of a group activity program for fibromyalgia patients on physical fitness and well-being J. Musculoskelet. Pain, 5 (4): 17-28, 1997.

25- HANDRAKIS J.P., FRIEL K., HOEFFNER F., AKINKUNLE O., GENOVA V., ISAKOV E. and VITULLI F.: Key Characteristics of Low Back Pain and Disability in College-Aged Adults: A Pilot Study. Archives of Physical Medicine and Rehabilitation, 93 (7): 121724, 2012.

26- ANDERSEN L.B., WEDDERKOPP N. and LEBOEUFYDE C.: Association between back pain and physical fitness in adolescents. Spine, 31 (15): 1740-4, 2006.

27- YOZBATIRAN N., YILDIRIM Y. and PARLAK B.: Effects of fitness and aqua fitness exercises on physical fitness in patients with chronic low back pain. Pain Clin., 16 (1): 35-42, 2004.

28- HARRISON R.A., HILLMAN M. and BULSTRODE S.: Loading of the lower limb when walking partially immersed: Implications for clinical practice. Physiotherapy, 78 (3): 164-6, 1992.

29- FOLEY A., HALBERT J. and HEWITT T.: Does hydrotherapy improve strength and physical function in patients with osteoarthritis-a randomized controlled trial comparing a gym based and hydrotherapy based strengthening program. Ann. Rheum. Dis., 62 (12): 1162-7, 2003.

30- MAHER C.G.: Effective physical treatment for chronic low back pain. Orthop. Clin. North Am., 35 (1): 57-64, 2004.

31- JOHNSON S.R., KEYAN Z. and ROSARIO E.R.: Effects of aquatic therapy on functional mobility and strength, fall risk, and self-reported disability in individuals with low back pain. Journal of Aquatic Physical Therapy, 24 (1): 22-31, 2016.

32- PRABHU C. and DADMI P.: Effect of aquatic therapy $\mathrm{v} / \mathrm{s}$ relaxation therapy in chronic low back pain. International Journal of Orthopaedics, 5 (1): 279-84, 2019.

33- COLADO J.C., TRIPLETT N.T., TELLA V., SAUCEDO P. and ABELL N.J.: Effects of aquatic resistance training on health and fitness in postmenopausal women. Eur. J. Appl. Physiol., 106 (1): 113-22, 2009.

34- FOSTER A.: A Study of Non-Specific Low Back Pain in a College Population including a Case Study Analysis of 
Physical Therapy Patient Data (Doctoral dissertation), 2016.

35- BAENA-BEATO P.A., ARROYO-MORALES M., DELGADO-FERNÊNDEZ M., GATTO-CARDIA M.C. and ARTERO E.G.: Effects of different frequencies (2-3 days/week) of aquatic therapy program in adults with chronic low back pain. A non-randomized comparison trial. Pain medicine, 14 (1): 145-158 abilitation, 93 (7): 1217-24, 2013.

36- GORDON R. and BLOXHAM S.: A systematic review of the effects of exercise and physical activity on nonspecific chronic low back pain. In Healthcare. Multidisciplinary Digital Publishing Institute, 4 (2): 22, 2016.

37- KARAGÜLLE M. and KARAGÜLLE M.Z.: Effectiveness of balneotherapy and spa therapy for the treatment of chronic low back pain: A review on latest evidence. Clin. Rheumatol., 34 (2): 207-14, 2015.
38- BARKER A.L., TALEVSKI J., MORELLO R.T., BRAND C.A., RAHMANN A.E. and URQUHART D.M.: Effectiveness of aquatic exercise for musculoskeletal conditions: A meta-analysis. Archives of physical medicine and rehabilitation, 95 (9): 1776-86, 2014.

39- DUNDAR U., SOLAK O., YIGIT I., EVCIK D. and KAVUNCU V.: Clinical effectiveness of aquatic exercise to treat chronic low back pain: A randomized controlled trial. Spine, 34 (14): 1436-40, 2009.

40- YOZBATIRAN N., YILDIRIM Y. and PARLAK: Bilge. Effects of fitness and aquafitness exercises on physical fitness in patients with chronic low back pain. The Pain clinic, 16 (1): 35-42, 2004.

41- SJOGREN T., LONG N., STORAY I. and SMITH J.: Group hydrotherapy versus group 1 and-based treatment for chronic low back pain. Physiother. Res. Int., 2 (4): 212-22, 1997.

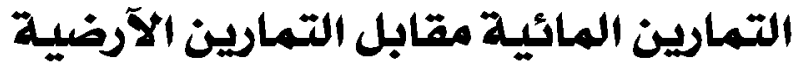

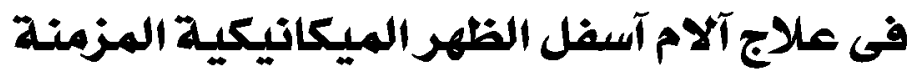

\author{
الخلفية: آلام آسفل الظهر الميكانيكية المزمنة هى سبب رئيسى المرض والعجز، وخاصة فى سن العمل. \\ الغرض : المقارنة بين تآثير التمارين المائية والتمارين الآرضية على الآلم، مدى الحركة والإعاقة الوظيفية فى الآشخاص المصابين بآلام \\ أسفل الظهر الميكانيكية المزمنة.

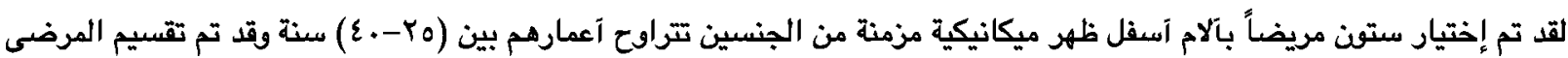

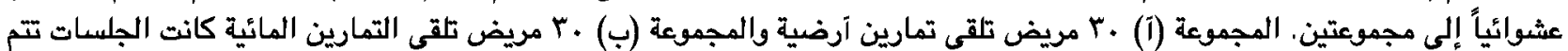

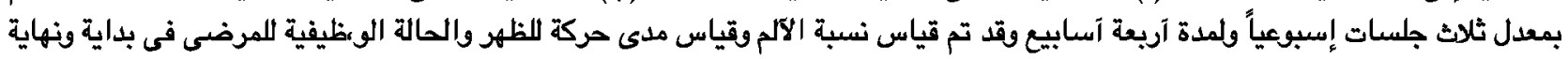 \\ الإثنى عشرة جلسة بإستخدام مقياس الآلم البصرى، مؤشر الإعاقة أوسويسترى وإختبار شوير المعدل.

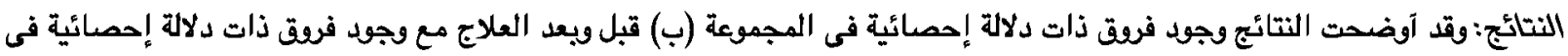

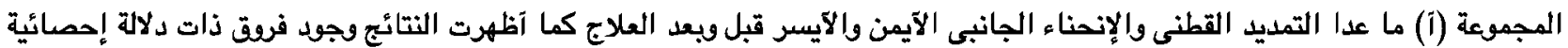 \\ أعلى لمجموعة التمارين المائية.
}

الخلاصة: التمارين المائية آكثر فاعلية من التمارين الآرضية في علاج آلام آسفل الظهر الميكانيكية المزمنة. 